\title{
What Affects Malaysian Consumers' Intention to Purchase Hybrid Car?
}

\author{
Teoh Chai Wen ${ }^{1} \&$ Nor Azila Mohd. Noor ${ }^{1}$ \\ ${ }^{1}$ Othman Yeop Abdullah Gradauate School of Business, Universiti Utara Malaysia, Sintok, Malaysia \\ Correspondence: Teoh Chai Wen, Othman Yeop Abdullah School of Business, Universiti Utara Malaysia, 06010 \\ Sintok, Malaysia. Tel: 60-16-966-8088. E-mail: chaiwen.teoh@gmail.com
}

Received: July 13, 2015 Accepted: August 5, $2015 \quad$ Online Published: August 28, 2015
$\begin{aligned} & \text { doi:10.5539/ass.v11n26p52 } \\ & \text { URL: http://dx.doi.org/10.5539/ass.v11n26p52 }\end{aligned}$

\begin{abstract}
The purpose of this study is to examine the factors influence consumers' intention to purchase hybrid car and explore the roles of consumption values in automotive context. The study has been examining the direct relationship between functional value, symbolic value, emotional value, novelty value and conditional value with consumers' intention to purchase hybrid car. Each variable was measured using 7-point Likert-scale. Questionnaire was used to collect data from individual consumers in Klang Valley. The data were then analyzed by using structural equation modeling (SEM) with SmartPLS 2.0. Five hypotheses were developed for this study and were tested using two stages analyses. The first stage involves measurement model while the second stage is structural model. The results of the study indicated that functional value is the most significant predictor of consumers' intention to purchase hybrid car. In contrast, symbolic value, emotional value and novelty value failed to show significant relationship with consumers' intention to purchase hybrid car. Finally, implications of the findings as well as limitations and future research are discussed.
\end{abstract}

Keywords: consumer intention, hybrid car, partial least squares, structural equation modeling, theory of consumption values

\section{Introduction}

As the environment continues to exasperate, developed countries found that environmental degradation is affecting their economy and policies whereas developing countries like Malaysia have just started the green movement as a step to preserve the environment (Ramayah, Lee, \& Osman, 2010). Developing countries like Malaysia start aware of the importance of green products which can reduce the environmental threat as well as boost the economy by creating opportunities for businesses. Consumers should responsible to the environmental degradation due to their consumption pattern. Environmental degradation not only caused by industry, consumers purchasing behavior and consumption pattern are also the reasons the environment continues to exasperate. Therefore, consumers could change the environment by consuming green products.

Apart from that, automotive industry is one of the most important industry in Malaysia. This is because automotive industry could contribute to the country's economy in terms of direct and indirect taxes, technology advancement, and the opportunity to grow other business, as well as human resources development by providing training and job opportunities. Malaysia is one of the largest automotive manufacturer in the world with more than half a million sales every year (Lim, 2012). Malaysia ranked as number three in ASEAN market, however the existence of green product could create an opportunity for Malaysia to become the market leader of automotive industry in ASEAN market.

In monitoring the automotive market, hybrid car is one of the green products that represent automotive industry. Hybrid car is the most popular green car in Malaysia in recent year. Malaysian consumers have showed their willingness to pay more for green products (Lung, 2010), however the usage of hybrid car is considered low. The first hybrid car available in Malaysia was in year 2007. Up to date, the total hybrid car registered in Malaysia since 2007 was around fifty thousand units. According to Mahalingam (2013), hybrid car sales are expected to be flat or lower. Therefore, there is a need to carry a study to examine the consumers' intention to purchase hybrid car before extra costs and investments incurred in manufacturing hybrid car and this study would contribute to local automotive manufacturers as well as foreign automotive manufacturers to emerge in Malaysia green market.

Apart from low usage of hybrid car, the diversity of factors in influence consumers' green purchase intention was 
arise. Previous studies have studied about the environmental factors (e.g. environmental knowledge, environmental attitudes, and environmental concern) and marketing factors (e.g. cost, quality, attitudes, and demographic), however there is a lack of value factors being examine especially consumption values. Value was found to be an important predictor in predicting consumers' purchase intention (Bui, 2005). Although intention is a good predictor of actual behavior, however without examine the values, it is still unable to provide a full picture of customer mind on consumer's purchase decision (Schiffman \& Kanuk, 1997). Therefore, consumption values was used to predict consumers' intention to purchase hybrid car in this study.

This study applied theory of consumption values developed by Sheth, Newman and Gross (1991) to examine the key determinants of consumers' intention especially in purchasing hybrid car. Most of the earlier studies regarding consumers' intention were employed theory of planned behavior or theory of reasoned action as the theoretical foundation. However, both theory of planned behavior and theory of reasoned action have it drawback. There are at least four limitations that have been identified by employing theory of planned behavior or theory of reasoned action. The first limitation is the determinant of intention should not limit to only attitudes, subjective norms and perceived behavioral control. The second limitation is the assumption of individuals are free to act without any limitation is often unfounded because limited ability, time, environment or unconscious habits would limit the freedom to act. The third limitation is values and environmental factors that may influence consumer's intention to perform a behavior does not take into account. The last limitation is theory of planned behavior or theory of reasoned action is a predictive model that predict individual's action based on certain criteria as individuals are not always behave as predicted and it might change over time especially when consumers take a longer time to carry out an intention, the behavior is less likely to occur. Therefore, two research questions are investigated in this study. First, we examine whether the consumption values (i.e. functional value, symbolic value, emotional value, novelty value and conditional value) drive or influence consumers' intention to purchase hybrid car. Second, we explore the roles of consumption value in automotive context. The next section of this paper will discusses the theoretical background and hypotheses development based on the theory of consumption values.

\section{Theoretical Background and Hypotheses Development}

One of the most successful strategies in 1990s was the ability of a company provides superior value to its customers (Wang, Liao, \& Yang, 2013). Value is consider as an important make up of relationship market. Value is the fundamental basis for all marketing activities. Value is the major sources of competitive advantage (Woodruff, 1997). Therefore, in order for a company to stay competitive in the market, company should create value to consumers as value become the concerned of consumers in performing purchase behavior.

Perceived value refers to an overall evaluation of benefit a consumer received from a product or service based on consumer's review (Bolton \& Drew, 1991; Patterson \& Spreng, 1997). Ramayah et al. (2010) mentioned that consumers generate behavior along with their beliefs and worldwide assumption. Previous research has widely explained the positive effect of perceived value on marketing performance (Sweeney, Soutar, \& Johnson, 1999). Perceived value was seen as an important predictor because companies are able to enhance consumer's intention to purchase through product value (Steenkamp \& Geyskens, 2006). Companies are able to deliver values by offering benefits and differentiating product from its competitors (Zeithaml, 1988; Aaker, 1996). According to Chen and Chang (2012), green perceived value would positively affect green purchase intention.

According to Sheth et al. (1991), perceived value is not limited to functional aspects of quality and price. Perceived value is a multi-dimensional approach. Perceived value had been empirically proved in marketing disciplines as multi-dimensional approach (Wang et al., 2013; Sheth et al., 1991). Among perceive value approaches, Sheth et al. (1991) is one of the most important contributor to perceived value studies (Sanchez-Fernandez \& Iniesta-Bonillo, 2007). Sheth et al. (1991) mentioned that consumer purchase choice entails a form of consumption values which can be categorized as functional, social, emotional, epistemic and conditional value, and each value plays a different roles in consumer's decision (Deng, Lu, Wei, \& Zhang, 2010). Therefore, theory of consumption values is more appropriate in explaining consumers' purchase intention. In this study, a proposed framework made up from various consumption values to predict consumer's intention to purchase hybrid car by using theory of consumption values. The research model is shown in Figure 1. 


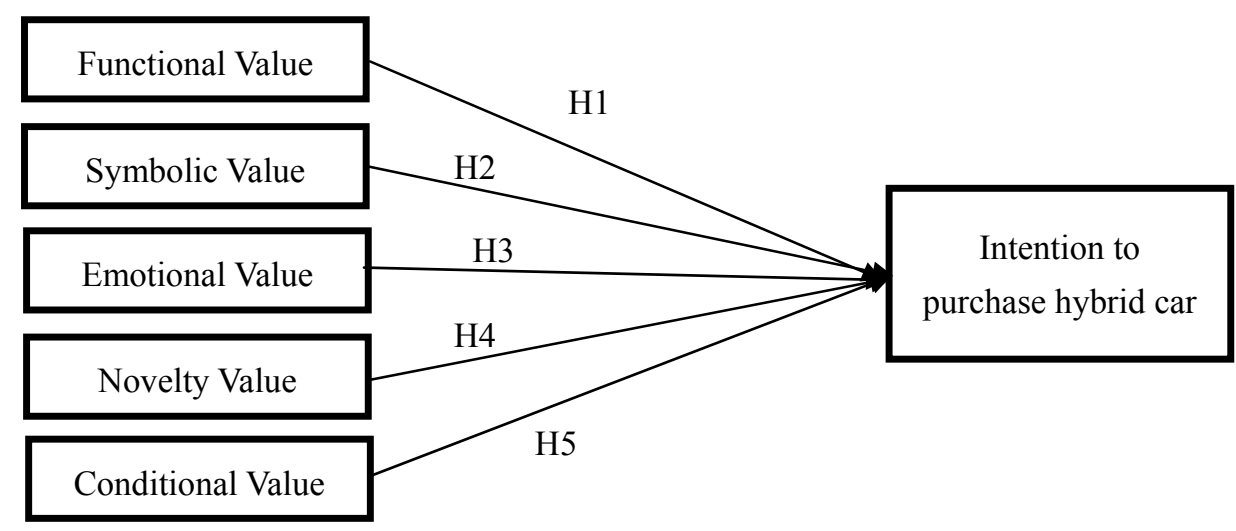

Figure 1. Research model

\subsection{Hypotheses Development}

The above literature has discussed the important concepts and useful studies in developing the framework for the present study. The next to be discussed is the relationship between the construct of the study.

\subsubsection{Functional Value}

Functional value was assumed as the primary driver of consumer choice (Sheth et al., 1991). Functional value has been conceptualized as the value received in terms of price and quality (Zeithaml, 1988; Dodds, Monroe, \& Grewal, 1991; Bolton \& Drew, 1991; Holbrook, 1994; Woodruff, 1997). Consumer's decision to purchase or use a product was influenced by the product attributes or product characteristics (Williams \& Soutar, 2009) and the fulfilment of consumer's utilitarian needs (Bødker, Gimpel, \& Hedman, 2009). Price has been found as the most salient functional value (Wang et al., 2013), however previous studies (e.g. Lin \& Huang, 2012; Lin, Huang \& Wang, 2010; Williams \& Soutar, 2009) found that functional value does not significant influence consumers' choice and purchase intention. On the other hand, Wang et al. (2013) found that functional value is positively affects the behavioral intention. Consequently, the proposed hypothesis is as follows.

H1. Functional value positively affects intention to purchase hybrid car.

\subsubsection{Symbolic Value}

Symbolic value has been described as "the meaning associated with the product and the image of the product" (Sheth et al., 1991). Symbolic value arises when individuals or groups share the meaning of a product, hence, the process in understanding and evaluating symbolic value is much more difficult than functional value (Burcu \& Seda, 2013). Oliver and Lee (2010) found that the relationship between social values with purchase intention on hybrid car was different according to cultures. The researcher found that social value would have positive effect on collectivism cultures. Malaysia is considered a highly collectivism society (Arfa Adlina, 2012). Previous studies (e.g. Lin \& Huang, 2012; Lin et al., 2010) found that social value does not significantly influence consumers' choice. However, two extra dimensions (i.e. self-identity and social influence) are added in the present study to test the symbolic value Therefore, the following hypothesis is makes:

H2. Symbolic value positively affects intention to purchase hybrid car.

\subsubsection{Emotional Value}

Emotional value refers to the ability of a product arouse feeling or affective states (Sheth et al., 1991). The feelings can be either positive (e.g. loyalty, nostalgia and excitement) or negative (e.g. anger, fear and guilt). Additionally, feelings also can be described as distinctive categories of emotional experience and expression by structural dimensions underlying emotional category. Human are associated with emotional responses in their daily life. Emotional value is one of the consumption values that influence consumers' decision where a product can stimulate emotions (Bødker et al., 2009). Previous studies (e.g. Lin \& Huang, 2012; Lin et al., 2010; Wang et al., 2013) found that emotional value is positively affects consumer choice behavior as well as behavioral intention. Hence, the following hypothesis is develops:

H3. Emotional value positively affects intention to purchase hybrid car. 


\subsubsection{Novelty Value}

A novelty value is created when the product or service arouses curiosity, provide originality or novelty and/or knowledge gaining (Sheth et al., 1991). Curiosity and innovative are explained by motivation theories as incentives existing in human nature (Burcu \& Seda, 2013). Hence, marketing experts accept that the incentives of "innovation and variety searching" are affected to consumers' purchase preferences (Burcu \& Seda, 2013). Previous studies (e.g. Lin \& Huang, 2012; Lin et al., 2010; Wang et al., 2013; Williams \& Soutar, 2009) found that epistemic value or novelty value is significantly affect consumer choice behavior and behavioral intention. Thus, the hypothesis is developed as below:

H4. Novelty value positively affects intention to purchase hybrid car.

\subsubsection{Conditional Value}

Conditional value means the benefits perceived or obtained in a certain condition the person making a preference come across (Sheth et al., 1991). Generally, consumers' conceptions of conditional value cannot be known until the condition that will change the behavior emerges (Burcu \& Seda, 2013). Conditional value was found to be the most influence predictor of consumers' choice behavior (e.g. Lin \& Huang, 2012; Lin et al., 2010). Hence, the following hypothesis is developed:

H5. Conditional value positively affects intention to purchase hybrid car.

\section{Research Method}

A quantitative method was employed for this study. A questionnaire was used to collect data on intention to purchase hybrid car with consumers from Klang Valley, Malaysia. The items used to measure the constructs in this study are adapted from previous study to ensure the content validity. Six items were used measure intention to purchase hybrid car is adapted from Sinnappan and Rahman (2011) and Kanchanapibul et al. (2014). Ten items were used to measure functional value is adapted from Hong et al. (2012) and Lin and Huang (2012). Twelve items were used to measure symbolic value is adapted from Oliver and Lee (2010); Sinnappan and Rahman (2011); Tan (2013) and Lee (2009). Emotional value is measured by eight items adapted from Williams and Soutar (2009); Sinnappan and Rahman (2011) and Lin and Huang (2012). Six items were adapted from Lin and Huang (2012) and Oliver and Lee (2010) to measure novelty values, whereas five items were adapted from Lin and Huang (2012) to measure conditional value. All the items are measured on a seven-point Likert scales. A pilot study was conducted using convenience sample with 30 drivers from three residential areas in South Klang, Selangor. The reliability for pilot test was ranged from 0.755 to 0.905 which are sufficient for research purpose (Nunnally, 1978).

\subsection{Data Collection Procedure}

The sampling procedure applied in this study was proportionate stratified sampling where the population is divided into groups according to the major city in Klang Valley such as Kuala Lumpur, Ampang Jaya, Petaling Jaya, Subang Jaya, Shah Alam and Klang. According to the Cohen's Rules of Thumb, the minimum sample size suggested for seven arrows pointing at one construct for PLS-SEM analysis is 228 (Hair, Hult, Ringle, \& Sarstedt, 2014). This study applied intercept method for data collection. As refer to previous research (e.g. Nor Azila, Hayatul, Noratisah, \& Azli, 2014) that applied intercept method, the response rate is 56.5 percent. Therefore, 404 sets of questionnaire were distributed. The respondents were required to fill up and return the questionnaire on the spot.

The self-administered questionnaire was distributed at the selected top three brands hybrid car seller (Honda, Toyota and Nissan) showrooms. Questionnaire was distributed outside the showrooms and approach individual consumer who walk out from the showroom after consulting the sales representative or sales admin. The reason of choosing individual consumer who visit showroom is because the probability of an individual intent to purchase a hybrid car is higher for those who went to showroom. Consumers who visited the showroom are not curious buyers (Capgemini, 2011).

From 404 sets of questionnaire sent, 352 questionnaires were returned. However, only 306 were usable. Forty six questionnaires were removed because of the respondents are hybrid car owner. Therefore, the usable response rate of 75.7 percent has achieved.

The demographic profile of respondents for this study are shown in Table 1. Among 306 valid respondents, 147 (48 percent) are male while 159 (52 percent) are female. Based on the survey, the highest respondent's age group falls between 21-38 years old ( 73.5 percent), followed by between $39-49$ years old (19.9 percent) and 50 years old and above (6.5 percent). 
Table 1. Demographic profile of respondents $(n=306)$

\begin{tabular}{|c|c|c|c|}
\hline Variable & Category & Frequency & Percentage \\
\hline \multirow[t]{2}{*}{ Gender } & Male & 147 & 48.0 \\
\hline & Female & 159 & 52.0 \\
\hline \multirow[t]{3}{*}{ Age } & $21-38$ & 225 & 73.5 \\
\hline & $39-49$ & 61 & 19.9 \\
\hline & 50 and above & 20 & 6.5 \\
\hline \multirow[t]{4}{*}{ Monthly Income } & Less than RM 2000 & 25 & 8.2 \\
\hline & RM 2001 - RM 4000 & 131 & 42.8 \\
\hline & RM 4001 - RM 6000 & 108 & 35.3 \\
\hline & RM 6001 and above & 42 & 13.7 \\
\hline \multirow[t]{5}{*}{ Employment Sector } & Government sector & 11 & 3.6 \\
\hline & Private sector & 227 & 74.2 \\
\hline & Self-employment & 62 & 20.3 \\
\hline & Student & 4 & 1.3 \\
\hline & Retirement & 2 & 0.7 \\
\hline \multirow[t]{6}{*}{ Qualification } & Primary school & 2 & 0.7 \\
\hline & Secondary school & 54 & 17.6 \\
\hline & Diploma & 88 & 28.8 \\
\hline & Bachelor's Degree & 121 & 39.5 \\
\hline & Master's Degree & 40 & 13.1 \\
\hline & Doctorate Degree / PhD & 1 & 0.3 \\
\hline \multirow[t]{8}{*}{ Brand Preference } & Toyota & 89 & 29.1 \\
\hline & Honda & 73 & 23.9 \\
\hline & Nissan & 32 & 10.5 \\
\hline & Lexus & 40 & 13.1 \\
\hline & AUDI & 37 & 12.1 \\
\hline & BMW & 21 & 6.9 \\
\hline & Porsche & 12 & 3.9 \\
\hline & Mercedes-Benz & 2 & 0.7 \\
\hline
\end{tabular}

\section{Analysis and Results}

Data analysis in structural equation modeling is divided into two steps (Ramayah, 2014; Anderson \& Gerbing, 1988). The first step involves analysis of measurement model where assessment of validity and reliability of the items was carried out. The second step involves analysis of structural model where assessment of relationship between the latent constructs and hypotheses are tested. Partial least squares (PLS) was used to carry out the analysis of measurement model and structural model is because PLS do not require a large sample size, does not require normal-distributed input data, can be applied for complex model, and is useful for prediction (Urbach \& Ahleman, 2010).

\subsection{Measurement Model}

Two types of validity were assessed in the measurement model which are convergent validity and discriminant validity as suggested by Hair et al. (2014). Convergent validity and reliability were assessed first in the measurement model. Composite reliability was used to test the construct reliability while average variance extracted (AVE) was used to assess the construct convergent validity. According to Hair et al. (2014), the threshold value for composite reliability is above 0.70 while the threshold value for AVE is 0.5 . Table 2 indicated 
that the AVE values and composite reliability were above the threshold value which shows that higher level of reliability and the constructs explain more than half of the variance of its indicators.

After convergent validity and reliability of each construct are confirmed, the next to be carried out is discriminant validity where to examine the degree to which the construct is truly different from the other construct in the study. Cross loadings and Fornell-Larcker criterion (correlation matrix) are carried out as suggested by Hair et al. (2014). Based on Table 3, the loading of each item is larger on its assigned latent variable that its loadings on other construct (Chin, 1998), this indicates a good discriminant validity. Thereafter, the square root of the average variance extracted (AVE) is compared with the latent variable correlations (Hair et al., 2014). As shown in Table 4, the values in the diagonal are much larger than the correlations shared between the construct. Therefore, discriminant validity was achieved.

Table 2. Convergent validity and reliability for the constructs

\begin{tabular}{ccc}
\hline & AVE & Composite Reliability \\
\hline Conditional Value (CV) & 0.659 & 0.905 \\
Emotional Value (EV) & 0.725 & 0.955 \\
Functional Value (FV) & 0.604 & 0.938 \\
Intention to Purchase Hybrid Car (Int) & 0.651 & 0.918 \\
Novelty Value (NV) & 0.792 & 0.958 \\
Symbolic Value (SV) & 0.598 & 0.930 \\
\hline
\end{tabular}

Table 3. Cross loadings

\begin{tabular}{lcccccc}
\hline & Conditional Value & Emotional Value & Functional Value & Intention & Novelty Value & Symbolic Value \\
\hline CV_1 & $\mathbf{0 . 6 5 6 6}$ & 0.5079 & 0.3885 & 0.4095 & 0.3929 & 0.4502 \\
CV_2 & $\mathbf{0 . 8 6 7 3}$ & 0.4774 & 0.4495 & 0.4574 & 0.5943 & 0.4457 \\
CV_3 & $\mathbf{0 . 8 4 2 5}$ & 0.4613 & 0.4322 & 0.4273 & 0.5636 & 0.4286 \\
CV_4 & $\mathbf{0 . 8 7 4 0}$ & 0.4999 & 0.4425 & 0.4790 & 0.5855 & 0.4488 \\
CV_5 & $\mathbf{0 . 7 9 8 5}$ & 0.6351 & 0.5466 & 0.6060 & 0.5490 & 0.6059 \\
EV_1 & 0.5645 & $\mathbf{0 . 8 5 8 2}$ & 0.6438 & 0.5713 & 0.5414 & 0.6833 \\
EV_2 & 0.6193 & $\mathbf{0 . 8 8 7 5}$ & 0.6672 & 0.6006 & 0.6174 & 0.7047 \\
EV_3 & 0.4735 & $\mathbf{0 . 8 2 0 7}$ & 0.5799 & 0.5338 & 0.4557 & 0.6214 \\
EV_4 & 0.5138 & $\mathbf{0 . 8 6 3 8}$ & 0.6531 & 0.5713 & 0.5061 & 0.6204 \\
EV_5 & 0.5306 & $\mathbf{0 . 8 4 8 9}$ & 0.6263 & 0.5691 & 0.5531 & 0.6133 \\
EV_6 & 0.5465 & $\mathbf{0 . 8 6 2 1}$ & 0.6539 & 0.5966 & 0.5960 & 0.6425 \\
EV_7 & 0.6003 & $\mathbf{0 . 8 9 5 4}$ & 0.5991 & 0.5571 & 0.5453 & 0.6332 \\
EV_8 & 0.5615 & $\mathbf{0 . 7 6 9 3}$ & 0.4566 & 0.4749 & 0.4526 & 0.5612 \\
FV_1 & 0.4313 & 0.5863 & $\mathbf{0 . 7 9 1 7}$ & 0.5280 & 0.5230 & 0.6122 \\
FV_2 & 0.2697 & 0.4731 & $\mathbf{0 . 6 7 8 4}$ & 0.5004 & 0.3285 & 0.5046 \\
FV_3 & 0.4200 & 0.5961 & $\mathbf{0 . 8 4 8 0}$ & 0.6053 & 0.4528 & 0.6225 \\
FV_4 & 0.4659 & 0.6506 & $\mathbf{0 . 8 7 5 3}$ & 0.6531 & 0.5144 & 0.6721 \\
FV_5 & 0.5795 & 0.6720 & $\mathbf{0 . 8 9 2 8}$ & 0.6733 & 0.6105 & 0.6834 \\
FV_6 & 0.5339 & 0.6812 & $\mathbf{0 . 8 9 3 8}$ & 0.6309 & 0.5457 & 0.6900 \\
FV_7 & 0.4579 & 0.4170 & $\mathbf{0 . 6 2 9 7}$ & 0.4061 & 0.6002 & 0.4913 \\
FV_8 & 0.2923 & 0.4911 & $\mathbf{0 . 7 2 6 0}$ & 0.5575 & 0.3347 & 0.4876 \\
FV_9 & 0.4843 & 0.5172 & $\mathbf{0 . 7 4 8 1}$ & 0.5272 & 0.5492 & 0.6070 \\
\hline
\end{tabular}




\begin{tabular}{|c|c|c|c|c|c|c|}
\hline & Conditional Value & Emotional Value & Functional Value & Intention & Novelty Value & Symbolic Value \\
\hline FV_10 & 0.4664 & 0.4390 & 0.6246 & 0.4398 & 0.5607 & 0.4686 \\
\hline Int_1 & 0.4619 & 0.4731 & 0.4766 & 0.7844 & 0.4612 & 0.4013 \\
\hline Int_2 & 0.4087 & 0.5559 & 0.5847 & 0.8319 & 0.4403 & 0.5226 \\
\hline Int_3 & 0.4262 & 0.4893 & 0.5128 & 0.7950 & 0.4267 & 0.4525 \\
\hline Int_4 & 0.4404 & 0.4606 & 0.5249 & 0.8066 & 0.4633 & 0.4275 \\
\hline Int_5 & 0.5078 & 0.5755 & 0.6665 & 0.7864 & 0.4361 & 0.5878 \\
\hline Int_6 & 0.6191 & 0.6014 & 0.6692 & 0.8346 & 0.5275 & 0.5954 \\
\hline NV_1 & 0.5758 & 0.5660 & 0.5822 & 0.5166 & 0.9127 & 0.5433 \\
\hline NV_2 & 0.5526 & 0.5500 & 0.5566 & 0.5048 & 0.9242 & 0.5375 \\
\hline NV_3 & 0.5890 & 0.6169 & 0.6175 & 0.5680 & 0.8975 & 0.6277 \\
\hline NV_4 & 0.6285 & 0.5953 & 0.6047 & 0.5430 & 0.9019 & 0.5844 \\
\hline NV_5 & 0.6182 & 0.5164 & 0.5350 & 0.4695 & 0.8612 & 0.5229 \\
\hline NV_6 & 0.6079 & 0.4996 & 0.5021 & 0.4288 & 0.8402 & 0.5189 \\
\hline SV_2 & 0.4880 & 0.5754 & 0.7171 & 0.5321 & 0.6576 & 0.7679 \\
\hline $\mathrm{SV} \_3$ & 0.4764 & 0.6093 & 0.6776 & 0.5286 & 0.5540 & 0.7996 \\
\hline SV_5 & 0.3837 & 0.4705 & 0.4432 & 0.3584 & 0.3948 & 0.7018 \\
\hline SV_6 & 0.4589 & 0.5553 & 0.4911 & 0.4502 & 0.3889 & 0.7924 \\
\hline $\mathrm{SV} \_7$ & 0.3591 & 0.4662 & 0.4724 & 0.4557 & 0.3173 & 0.7226 \\
\hline SV_8 & 0.4062 & 0.5541 & 0.5216 & 0.4624 & 0.3524 & 0.7650 \\
\hline $\mathrm{SV} \_10$ & 0.5533 & 0.6757 & 0.6736 & 0.5573 & 0.5780 & 0.8403 \\
\hline SV_11 & 0.5540 & 0.6660 & 0.6663 & 0.5507 & 0.5694 & 0.8456 \\
\hline SV_12 & 0.4451 & 0.5909 & 0.5300 & 0.4181 & 0.4780 & 0.7117 \\
\hline
\end{tabular}

Table 4. Correlation matrix

\begin{tabular}{ccccccc}
\hline & CV & EV & FV & Int & NV & SV \\
\hline Conditional Value (CV) & $\mathbf{0 . 8 1 1 7}$ & & & & & \\
Emotional Value (EV) & 0.6471 & $\mathbf{0 . 8 5 1 6}$ & & & & \\
Functional Value (FV) & 0.5667 & 0.7201 & $\mathbf{0 . 7 7 7 2}$ & & & \\
Intention to Purchase Hybrid Car (Int) & 0.5997 & 0.6587 & 0.7195 & $\mathbf{0 . 8 0 6 7}$ & & \\
Novelty Value (NV) & 0.6673 & 0.6293 & 0.6392 & 0.5712 & $\mathbf{0 . 8 9 0 1}$ & \\
Symbolic Value (SV) & 0.5983 & 0.7471 & 0.7573 & 0.6272 & 0.6269 & $\mathbf{0 . 7 7 3 5}$
\end{tabular}

Note: Diagonals represent the square root of the average variance extracted while the other entries represent the correlations

\subsection{Structural Model}

The next step after measurement model is structural model. Hypotheses were tested in this step. R2 values and path coefficient were obtained by running the PLS algorithm and bootstrapping with 5000 samples and 306 cases. The results are presented in Table 5 and Figure 2. The $\mathrm{R}^{2}$ values of 0.586 means the five values explained 58.6 percent of the variance of intention to purchase hybrid car. Table 5 shows that only hypotheses were supported. 
Table 5. Path coefficients and hypotheses testing

\begin{tabular}{llccc}
\hline Hypothesis & Relationship & $\begin{array}{c}\text { Path } \\
\text { Coefficient }\end{array}$ & t-value & Decision \\
\hline H1 & Functional value -> Intention to purchase hybrid car & 0.446 & $6.781^{* *}$ & Supported \\
H2 & Symbolic value -> Intention to purchase hybrid car & 0.021 & 0.310 & Not Supported \\
H3 & Emotional value -> Intention to purchase hybrid car & 0.172 & $2.713^{* *}$ & Supported \\
H4 & Novelty value -> Intention to purchase hybrid car & 0.029 & 0.428 & Not Supported \\
H5 & Conditional value -> Intention to purchase hybrid car & 0.204 & $3.348^{* *}$ & Supported \\
\hline
\end{tabular}

Note: $* * p<0.01$

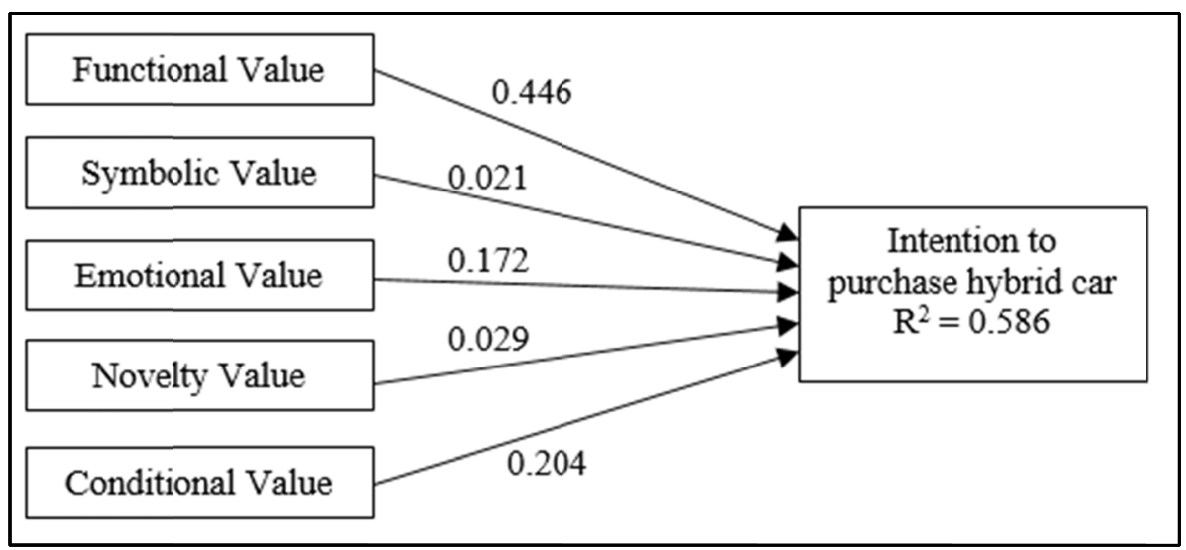

Figure 2. Results of the structural model analysis

\section{Discussion and Implication}

As hypothesized, the results of this study confirm that functional value, emotional value and conditional value have significant effects on intention to purchase hybrid car. Among the significant values, the influences of functional value is stronger than conditional value and emotional value. According to the respondents, Toyota is the most preferable brand that Malaysian consumers prefer to purchase for hybrid car. Consumers' intention to purchase hybrid car might result from the functional attributes of hybrid car in terms of maintenance cost, price and quality when manufacturer or government do offer discount, promotion or subsidy for hybrid car purchase and their emotional needs can be satisfied through purchasing hybrid car. Additionally, the respondents of this study shows that their willingness to purchase hybrid car with higher price is consistent with a market survey reported by Lung (2010). The increased of fuel price can be one of the reasons consumers purchasing hybrid car.

The results show that symbolic value and novelty value have not significant effects on intention to purchase hybrid car. The possible reason that symbolic value is not significant is because respondents did not feel that their social approval, status or impression can be increased through purchasing hybrid car. Malaysia is slightly move from collectivism country to become individualism country. As country become individualism, personal belief become consumers' main concern and the decision will be based on their personal belief rather than social groups' advice. Therefore, symbolic value become less important.

On the other hand, novelty value is also found to be insignificant with intention to purchase hybrid car. In the $21^{\text {st }}$ century, most of the consumers are educated at least to secondary school level. Consumers are normally with little knowledge and they are able to get specific knowledge through internet. Therefore, promotion become important to increase consumers' awareness about the product rather than educate the knowledge of product to consumers.

Based on the findings of this study, 58.6 percent of consumer's behavior is explained by the five consumption values which is better than theory such as theory of planned behavior. The findings of this study is not in line with previous study such as Alesia Sigang, Sondah, \& Geoffrey Harvey (2014). In Alesia Sigang et al. (2014) studied, there is a significant relationships between consumption values and purchase intention in green product context. On the other hand, Lin et al. (2010); Lin and Huang (2012) found that functional value and social value 
are not significantly influence choice behavior while emotional value, epistemic value and conditional value are significantly influence choice behavior toward green products. This shows an inconsistent between the findings of this study and previous studies.

\subsection{Managerial Implications}

The research findings have provided some insight to marketer on the way to attract consumers with the appropriate values as product values has been identify as important factors in influencing consumers' purchase intention. Marketers should aware that functional value and conditional value does influence consumers' intention to purchase hybrid car.

Based on the findings, marketers should not concentrate too much on social influence as their strategy go attract Malaysian consumers to purchase hybrid car because symbolic value does not show significant relationship in influencing consumers' intention to purchase hybrid car.

Besides, government's subsidy and manufacturers' promotion or discount could create consumers' intention to purchase hybrid car. Therefore, Malaysia government should consider to implement another policy such as tax exemption which could boost the hybrid car sales and it can help in achieving one of the objectives of National Automotive Policy to become the regional hub of energy efficient vehicles.

\section{Limitation and Suggestions for Future Research}

As this study is based on cross-sectional data where data was collected once in a specific time which is unable to provide a better insight and understanding of consumers' intention. This is because consumers' intention might change over time and there is a time interval for consumers to carry an action. In order to better understand consumers' purchase behavior and the significant variables that influence consumers' intention might be different in long run. Hence, longitudinal research is recommended in future research.

Besides, the data of this study was collected from Klang Valley consumers' which is unable to represent the whole population of Malaysia especially the different between Peninsula Malaysia or East Coast and West Coast of Malaysia. Therefore, future research suggest that a cross-culture study where a comparison between West Coast and Each Coast of Malaysia should be carrying out. This is because consumers in East Coast and West Coast having different living lifestyle, culture, economy and development level. Therefore, cross-culture study enable marketers to apply appropriate marketing strategies to each coast.

Lastly, this study is based on theory of consumption values instead of the popular theory such as theory of planned behavior or theory of reasoned action. However, the theory of consumption values is able to explain 58.6 percent of behavioral intention in this study while as mentioned earlier only 40 percent of the behavioral intention is explained by theory of planned behavior or theory of reasoned action. Therefore, future research should consider theory of consumption values.

\section{References}

Aaker, D. A. (1996). Building Strong Brands. The Free Press. New York, NY.

Anderson, J. C., \& Gerbing, D. W. (1988). Structural equation modeling in practice: A review and recommended two-step approach. Psychological bulletin, 103(3), 411. http://dx.doi.org/10.1037/0033-2909.103.3.411

Arfa Adlina, A. (2012). Malaysia \& the collectivist culture: Malaysian studies. Kolej Yayasan UEM, Malaysia. Retrieved from http://www.slideshare.net/ArfaAyob/malaysia-and-collectivism

Alesia Sigang, G., Sondoh, S. L., \& Geoffrey Harvey, T. (2014, May). Consumption values, environmental concern, attitude and purchase intention in the context of green products. Paper session presented at the 2014 International Conference of the Association of Global Management Studies, UK.

Bødker, M., Gimpel, G., \& Hedman, J. (2009). The user experience of smart phones: A consumption values approach. Paper presented at Global Mobility Roundtable, Kairo, Egypt.

Bolton, R. N., \& Drew, J. H. (1991). A multistage model of consumers' assessment of service quality and value. Journal of Consumer Research, 17(4), 375-384. http://dx.doi.org/10.1086/208564

Bui, M. H. (2005). Environmental marketing: A model of consumer behavior. Advances in Marketing, 6(2), $20-28$.

Burcu, C., \& Seda, Y. (2013). Investigating the relationship between consumption values and personal values of green product buyers. International Journal of Economics and Management Sciences, 2(12), 29-40. Retrieved from http://www.academia.edu/6428262/Investigating_the_Relationship_between_Consumption_ Values_and_Personal_Values_of_Green_Product_Buyers 
Capgemini. (2011). Cars online11/12: Changing dynamics drive new developments in technology and business models. Retrieved from https://www.ca.capgemini.com/resource-file-access/resource/pdf/Cars_Online_ 11_12.pdf

Chen, Y. S., \& Chang, C. H. (2012). Enhance green purchase intentions: The roles of green perceived value, green perceived risk, and green trust. Management Decision, 50(3), 502-520. http://dx.doi.org/10.1108/002 51741211216250

Chin, W. W. (1998). The Partial Least Squares Approach to Structural Equation Modeling. In G. A. Marcoulides (Ed.), Modern Methods for Business Research (pp. 295-336). Mahwah, NJ, US: Lawrence Erlbaum Associates Publishers

Deng, Z., Lu, Y., Wei, K. K., \& Zhang, J. (2010). Understanding customer satisfaction and loyalty: An empirical study of mobile instant messages in China. International Journal of Information Management, 30(4), 289-300. http://dx.doi.org/10.1016/j.ijinfomgt.2009.10.001

Dodds, W. B., Monroe, K. B., \& Grewal, D. (1991). Effects of price, brand, and store information on buyers' product evaluations. Journal of Marketing Research, 28(3), 307-319. http://dx.doi.org/10.2307/3172866

Hair, J. F., Hult, G. T. M., Ringle, C. M., \& Sarstedt, M. (2014). A primer on partial least squares structural equation modeling (PLS-SEM). Thousand Oaks, CA: SAGE Publications.

Holbrook, M. B. (1994). The nature of customer value: An axiology of services in the consumption experience. In R. T. Rust, \& R. L. Oliver (Eds.), Service quality: New directions in theory and practice (pp. 21-71). London: SAGE Publications.

Kanchanapibul, M., Lacka, E., Wang, X., \& Chan, H. K. (2014). An empirical investigation of green purchase behaviour among the young generation. Journal of Cleaner Production, 66, 528-536. http://dx.doi.org/10.1016/j.jclepro.2013.10.062

Lee, K. (2009). Gender differences in Hong Kong adolescent consumers' green purchasing behavior. Journal of Consumer Marketing, 26(2), 87-96. http://dx.doi.org/10.1108/07363760910940456

Lim, M. (2012). "Market Watch 2012". The Malaysian Automotive and Supplier Industry. The German chamber network-MGC. Retrieved from http://www.malaysia.ahk.de/fileadmin/ahk_malaysia/Market_reports_2012/ Market_Watch_2012_-_Automotive.pdf

Lin, P. C., \& Huang, Y. H. (2012). The influence factors on choice behavior regarding green products based on the theory of consumption values. Journal of Cleaner Production, 22, 11-18. http://dx.doi.org/10.1016/j. jclepro.2011.10.002

Lin, P., Huang, Y., \& Wang, J. (2010). Applying the theory of consumption values to choice behavior toward green products. Management of Innovation and Technology (ICMIT), 2010 IEEE International Conference on IEEE, 348-353. http://dx.doi.org/10.1109/ICMIT.2010.5492714

Lung, S. (2010). Green Consumerism - The Way to Effectively Differentiate Your Products in Asia-Pacific Market. Retrieved from http://ezinearticles.com/?Green-Consumerism---The-Way-to-Effectively-Differ entiate-Your-Products-in-Asia-Pacific-Market\&id=4875312

Mahalingam, E. (2013, July 29). Hybrid vehicle sales seen flat or lower. The Star Online. Retrieved from http://www.thestar.com.my/Business/Business-News/2013/07/29/Hybrid-vehicle-sales-seen-flat-or-lower.as $\mathrm{px} /$

Nor Azila, M. N., Hayatul, S. S., Noratisah, M. N., \& Azli, M. (2014). Functional food product consumption among Malaysian consumers: The relationship between intention and actual behaviour. Proceedings of the Australian Academy of Business and Social Sciences Conference 2014. Retrieved from https://www.aabss.org.au/system/files/published/AABSS2014_238.pdf

Nunnally, J. C. (1978). Psychometric theory (2nd ed.). New York: McGraw-Hill.

Oliver, J. D., \& Lee, S. H. (2010). Hybrid car purchase intentions: A cross-cultural analysis. Journal of Consumer Marketing, 27(2), 96-103. http://dx.doi.org/10.1108/07363761011027204

Patterson, P., \& Spreng, R. (1997). Modeling the relationship between perceived value, satisfaction and repurchase intention in a business-to-business, service context: An empirical examination. International Journal of Service Industry Management, 8(5), 414-434. http://dx.doi.org/10.1108/09564239710189835

Ramayah, T. (2014). SmartPLS 2.0. Malaysia: Institute of Postgraduate Studies, Universiti Sains Malaysia. 
Ramayah, T., Lee, J. W. C., \& Osman, M. (2010). Green product purchase intention: Some insights from a developing country. Resources, Conservation and Recycling, 54(12), 1419-1427. http://dx.doi.org/10.101/j. resconrec.2010.06.007

Sanchez-Fernandez, R., \& Iniesta-Bonillo, M. (2007). The concept of perceived value: A systematic review of the research. Marketing Theory, 7(4), 427-451. http://dx.doi.org/10.1177/1470593107083165

Schiffman, L. G., \& Kanuk, L. L. (1997). Consumer Behaviour (6th ed.). NJ: Prentice-Hall.

Sheth, J. N., Newman, B. I., \& Gross, B. L. (1991). Why we buy what we buy: A theory of consumption values. Journal of Business Research, 22(2), 159-170. http://dx.doi.org/10.1016/0148-2963(91)90050-8

Sinnappan, P., \& Rahman, A. A. (2011). Antecedents of green purchasing behavior among Malaysian consumers. International Business Management, 5(3), 129-139. http://dx.doi.org/10.3923/ibm.2011.129.139

Steenkamp, J. B. E. M., \& Geyskens, I. (2006). How country characteristics affect the perceived value of web sites. Journal of Marketing, 70(3), 136-150. http://dx.doi.org/10.1509/jmkg.70.3.136

Sweeney, J. C., Soutar, G. N., \& Johnson, L. W. (1999). The role of perceived risk in the quality-value relationship: A study in a retail environment. Journal of Retailing, 75(1), 77-105. http://dx.doi.org/10.1016/ S0022-4359(99)80005-0

Tan, T. H. (2013). Use of structural equation modeling to predict the intention to purchase green and sustainable homes in Malaysia. Asian Social Science, 9(10), 181-191. http://dx.doi.org/10.5539/ass.v9n10p181

Urbach, N., \& Ahlemann, F. (2010). Structural equation modeling in information systems research using partial least squares. Journal of Information Technology Theory and Application, 11(2), 5-40. Retrieved from http://aisel.aisnet.org/cgi/viewcontent.cgi?article=1247\& context=jitta

Wang, H. Y., Liao, C., \& Yang, L. H. (2013). What affects mobile application use? The roles of consumption values. International Journal of Marketing Studies, 5(2), 11-22. http://dx.doi.org/10.5539/ijms.v5n2p11

Williams, P., \& Soutar, G. N. (2009). Value, satisfaction and behavioural intentions in an adventure tourism context. Annals of Tourism Research, 36(3), 413-438. http://dx.doi.org/10.1016/j.annals.2009.02.002

Woodruff, R. B. (1997). Customer value: The next source of competitive advantage. Journal of the Academy of Marketing Science, 25(2). 139-153. http://dx.doi.org/10.1007/BF02894350

Zeithaml, V. A. (1988). Consumer perceptions of price, quality, and value: A means-end model and synthesis of evidence. Journal of Marketing, 52(3), 2-22. Retrieved from http://areas.kenan-flagler.unc.edu/Marketing/ FacultyStaff/zeithaml/Selected\%20Publications/Consumer\%20Perceptions\%20of\%20Price,\%20Quality,\%2 0and\%20Value-\%20A\%20Means-End\%20Model\%20and\%20Snthesis\%20of\%20Evidence.pdf

\section{Appendix A}

\section{Questionnaire items}

Intention to purchase hybrid car

1. I intend to purchase a hybrid car because it is environmentally-friendly.

2. I intend to purchase a hybrid car even though it is more expensive than a conventional car.

3. I intend to purchase a hybrid car over a conventional car when their product qualities are similar.

4. I feel that I will play a great part in helping the environment if I drive a hybrid car.

5. I feel more comfortable if I drive a hybrid car rather than a conventional car.

6. I intend to buy a hybrid car in the near future.

Functional value

1. The hybrid car offers value for money.

2. The hybrid car is reasonably priced.

3. The hybrid car performs better.

4. The hybrid car is well made.

5. The hybrid car has an acceptable standard of quality.

6. The hybrid car performs consistently.

7. The hybrid car is better in fuel efficiency.

8. The hybrid car lowers my maintenance cost. 
9. The hybrid car is economical driving.

10. The hybrid car consumes less petrol.

Symbolic value

1. If I buy a hybrid car, most people who are important to me will disapprove it.

2. If I buy a hybrid car, most people who are important to me will appreciate it.

3. If I buy a hybrid car, most people who are important to me will find it desirable.

4. If I buy a hybrid car, most people who are important to me will not support it.

5. I learned so much about the hybrid car from my friends and family.

6. Most members of my family and friends will expect me to buy a hybrid car.

7. I will follow the advice of my family that I should buy a hybrid car.

8. My friends recommend e that I should buy a hybrid car.

9. Buying a hybrid car would have a negative effect on my self-image.

10. Buying a hybrid car would say something positive about who I am.

11. Buying a hybrid car would say something positive about what I stand for.

12. I feel proud of being a green person.

Emotional value

1. Buying a hybrid car will give me feelings of well-being.

2. Buying a hybrid car is exciting.

3. Buying a hybrid car will make me elated.

4. Buying a hybrid car will make me feel happy.

5. Buying a hybrid car will give me feelings of making a good personal contribution to something better.

6. Buying a hybrid car will give me feelings of doing the morally right thing.

7. Buying a hybrid car will give me feelings of being a better person.

8. I emotionally support the hybrid car.

Novelty value

1. Before buying a hybrid car, I will obtain substantial information about the different makes and models of products.

2. I will acquire a great deal of information about the different makes and models before buying a hybrid car.

3. I am willing to seek out novel information about the hybrid cars.

4. I like to search for new and different knowledge about the hybrid cars.

5. I know that hybrid cars can reduce the pollution level.

6. I know that hybrid cars can reduce environmental harm.

\section{Conditional value}

1. I will buy a hybrid car under worsening environmental conditions.

2. I will buy a hybrid car when there is a subsidy by the government for the hybrid car.

3. I will buy a hybrid car when there is a discount rate for the hybrid car.

4. I will buy a hybrid car when there is a promotional activity for the hybrid car.

5. I will buy a hybrid car when hybrid cars are available.

\section{Copyrights}

Copyright for this article is retained by the author(s), with first publication rights granted to the journal.

This is an open-access article distributed under the terms and conditions of the Creative Commons Attribution license (http://creativecommons.org/licenses/by/3.0/). 